\title{
Nephrolithiasis in patients with inflammatory bowel disease in the community
}

This article was published in the following Dove Press journal: International Journal of Nephrology and Renovascular Disease 26 July 2013

Number of times this article has been viewed

\author{
Dídia Bismara Cury ${ }^{1,2}$ \\ Alan C Moss ${ }^{2}$ \\ Nestor Schor ${ }^{3}$ \\ 'Scope Clinic, Campo Grande, Brazil; \\ ${ }^{2}$ Center for Inflammatory Bowel \\ Diseases, Beth Israel Deaconess \\ Medical Center, Harvard Medical \\ School, Boston, MA, USA; ${ }^{3}$ Division \\ of Nephrology, Federal University \\ of São Paulo, São Paulo, Brazil
}

Correspondence: Dídia Bismara Cury Rua Maracaju I 148, Jardim dos Estados, Campo Grande, MS 79002 212, Brazil Tel +55 6733256040

Email didia_cury@uol.com.br
Background: Inflammatory bowel disease (IBD) has been associated with renal stone formation. The objective of this study was to determine prospectively the prevalence of nephrolithiasis in a community-based population of patients with IBD and to analyze factors associated with renal calculus formation.

Methods: Screening renal ultrasound was performed in a well characterized cohort of patients seen between 2009 and 2012 at an IBD clinic. We enrolled 168 patients, including 93 with Crohn's disease and 75 with ulcerative colitis. Clinical and phenotypic variables associated with asymptomatic nephrolithiasis were determined.

Results: Nephrolithiasis was detected in 36 patients with Crohn's disease and in 28 patients with ulcerative colitis ( $38 \%$ for both). Although none of the patients had been previously hospitalized for symptomatic nephrolithiasis, nine with Crohn's disease and five with ulcerative colitis had recurrent urinary tract infections or hydronephrosis. In patients with Crohn's disease, ileocolonic (L3) disease was associated with a greater risk of nephrolithiasis than was ileal (L1) or colonic (L2) disease (odds ratio [OR] 2.3, 95\% confidence interval [CI] 1.8-7). Active ulcerative colitis (regardless of severity) represented a significant risk factor for formation of renal calculi (OR $4.2,95 \%$ CI $1.1-15, P=0.02$ ).

Conclusion: In surgery-naïve patients with IBD in the community, asymptomatic nephrolithiasis is common and should be considered when renal dysfunction or infection is detected.

Keywords: clinical activity indices, Crohn's disease, inflammatory bowel disease, nephrolithiasis, ulcerative colitis

\section{Introduction}

Nephrolithiasis represents a serious health problem in some countries. For instance, it has been reported that $5 \%-15 \%$ of the general population in the United States will develop renal calculi in their lifetime, with the five-year recurrence rate ranging from $30 \%$ to $50 \%$. Diet and gender are considered to be risk factors for the development of renal calculi, the incidence of which is higher in males. In the United States, nephrolithiasis accounts for $1 \%$ of all hospitalizations and is responsible for annual medical costs of two billion dollars. ${ }^{1-4}$

Chronic diseases that are accompanied by intermittent diarrhea, such as ulcerative colitis and Crohn's disease, are directly associated with the formation of renal calculi. Historical studies have demonstrated that the prevalence of symptomatic nephrolithiasis is higher in patients with inflammatory bowel disease (IBD, 7\%-15\%) than in the general population $(1 \%-15 \%)$, typically in patients who have undergone extensive small bowel resection or in those with persistent severe small bowel inflammation. ${ }^{5,6}$ 
Extensive small bowel resections can lead to steatorrhea and increase the risk of hyperoxaluria by $28 \%$, because these interventions can lead to loss of the bacterium Oxalobacter formigenes or chelation of free calcium in the colonic lumen by lipids. ${ }^{7}$ In addition, it has been reported that patients who have an ostomy are more likely to develop uric acid stones than calcium oxalate stones. ${ }^{6,8,9}$

In the last 10 years, new therapeutic approaches to patients with IBD have emerged and completely changed the natural history of these diseases; the impact of such approaches is reflected not only in lower rates of surgery but also in better prognoses, fewer hospitalizations, and better improved quality of life. ${ }^{9}$ Whether this has changed the prevalence of and risk factors for renal calculi in this patient population is unknown.

The objective of the present study was to determine prospectively the prevalence of nephrolithiasis in a communitybased population of patients with IBD who had not undergone surgery. In addition, we sought to identify risk factors for formation of renal calculi in this population.

\section{Materials and methods}

We investigated a community-based population of patients with IBD treated between 2009 and 2012 at a clinic in the city of Campo Grande, located in the central-west region of Brazil. This was an analysis of prospectively collected data. Patients with ulcerative colitis were classified as having proctosigmoiditis, left-sided colitis, or pancolitis, whereas patients with Crohn's disease were classified in accordance with the Vienna classification of Crohn's disease. We determined disease activity using the Truelove-Witts index for patients with ulcerative colitis and the Crohn's Disease Activity Index for patients with Crohn's disease at the time of the index visit.

At the first appointment with the gastroenterologist, an ultrasound of the kidneys and urinary tract was requested in order to screen for renal calculi, as is the clinical practice of the treating physician (DC). On the basis of the results, all patients with calculi or hydronephrosis were referred to a nephrologist for follow-up evaluation. We analyzed the electronic medical records of 168 patients monitored during the 12-month study period. The study was approved by the Universidade de São Paulo ethics committee (182330).

\section{Statistical analysis}

Continuous variables are presented as the mean and standard deviation, and categorical variables are presented as percentages. We used the Student's $t$-test to analyze continuous variables, and used the chi-square test or Fisher's exact test to analyze categorical variables. Odds ratios were calculated using $2 \times 2$ tables of frequencies. All multivariate logistic regression analysis was undertaken for all variables significantly $(P<0.1)$ associated with the presence of renal calculi. Data were analyzed using the JMP program (SAS Institute, Cary, NC, USA)

\section{Results}

Of the 168 patients analyzed, 93 had Crohn's disease and 75 had ulcerative colitis. Table 1 outlines their baseline characteristics, which are typical for the IBD population at this clinic. The mean age was 42 years, and females accounted for $52 \%$ of the patients with Crohn's disease and $75 \%$ of those with ulcerative colitis. Overall, $16 \%$ of patients with ulcerative colitis had active disease at the time of enrollment, and the distribution of disease was as expected for IBD. Only two of the cohort, both with Crohn's disease, had a history of prior ileal resection.

The prevalence of nephrolithiasis in the patients with Crohn's disease was 38\% compared with $38 \%$ for those with ulcerative colitis. The prevalence of hydronephrosis was $10 \%$ in the patients with Crohn's disease and $13 \%$ in those with ulcerative colitis. Although none of the patients had been previously hospitalized for symptomatic nephrolithiasis, nine patients with Crohn's disease and five with ulcerative colitis (the same patients who developed hydronephrosis) had a history of recurrent urinary tract infection.

The univariate factors associated with nephrolithiasis are detailed in Table 2. Nephrolithiasis was more prevalent in patients with ileocolonic (L3) disease than in those with other subtypes of Crohn's disease, including ileal disease

Table I Baseline characteristics of patients

\begin{tabular}{lll}
\hline Variable & CD (n= 93) & UC ( $\mathbf{n = 7 5 )}$ \\
\hline Mean age (years) & 41 & 43 \\
Female (\%) & 52 & 75 \\
Prior surgery (\%) & 2 & 0 \\
Disease geography (\%) & & \\
$\quad$ lleal disease & 69 & 0 \\
Pancolitis & 0 & 21 \\
Active at enrollment (\%) & 24 & 16 \\
Current medications (\%) & & \\
$\quad$ Mesalazine & 98 & 100 \\
Prednisone & 50 & 47 \\
Thiopurine & 42 & 37 \\
Anti-TNF & 36 & 4 \\
Methotrexate & 18 & 2 \\
Antibiotics & 24 & 8 \\
\hline
\end{tabular}

Abbreviations: CD, Crohn's disease; UC, ulcerative colitis; TNF, tumor necrosis factor. 
Table 2 Univariate factors associated with renal calculi

\begin{tabular}{|c|c|c|}
\hline Variable & $C D(n=93)$ & UC $(n=75)$ \\
\hline Disease activity (UC) & - & $\begin{array}{l}\text { OR } 4.2(95 \% \mathrm{Cl} \\
\mathrm{I} . \mathrm{I}-15, P=0.02)\end{array}$ \\
\hline Disease location (L3) & $\begin{array}{l}\text { OR } 2.3(95 \% \mathrm{Cl} \\
\text { I.8-7, } P=0.007)\end{array}$ & - \\
\hline Steroids & - & $\begin{array}{l}\text { OR } 2.9(95 \% \mathrm{Cl} \\
\text { I.I-7, } P=0.03)\end{array}$ \\
\hline Ciprofloxacin & $\begin{array}{l}\text { OR } 5.2(95 \% \mathrm{Cl} \\
\text { I.9-14, } P=0.002)\end{array}$ & $\begin{array}{l}\text { OR I0 }(95 \% \mathrm{Cl} \\
\mathrm{I} . \mathrm{I}-90, P=0.03)\end{array}$ \\
\hline Immunomodulator & $\begin{array}{l}\text { OR } 4.2(1.7-10 \\
P=0.001)\end{array}$ & $\begin{array}{l}\text { OR } 3.9(95 \% \mathrm{Cl} \\
\text { I.4-10, } P=0.006)\end{array}$ \\
\hline Metronidazole & $\begin{array}{l}\text { OR } 3.5(95 \% \mathrm{Cl} \\
\text { I.3-9.8, } P=0.002)\end{array}$ & $\begin{array}{l}\text { OR I2 }(95 \% \mathrm{Cl} \\
1.5-110, P=0.01)\end{array}$ \\
\hline Methotrexate & $\begin{array}{l}\text { OR } 3.8(95 \% \mathrm{Cl} \\
\mathrm{I} .3-1 \mathrm{I}, \mathrm{P}=0.0 \mathrm{I})\end{array}$ & - \\
\hline
\end{tabular}

Abbreviations: $C D$, Crohn's disease; UC, ulcerative colitis; OR, odds ratio; $\mathrm{Cl}$, confidence interval.

only (odds ratio 2.3, $P=0.007$ ). The numbers of patients with prior surgery $(2 \%)$ was insufficient to draw conclusions about its association with formation of renal calculi in patients with Crohn's disease. In patients with ulcerative colitis, extent of disease was not significantly associated with nephrolithiasis $(P=0.195)$. However, active ulcerative colitis represented a significant risk factor for formation of renal calculi (odds ratio $4.2,95 \%$ confidence interval $1.1-15, P=0.02$ ). In all patients with IBD, any medication use was associated with renal calculi, although this association was not significant when controlled for disease activity.

\section{Discussion}

Inflammatory bowel disease is typically accompanied by diarrhea and malabsorption, both of which are predisposing factors for formation of renal calculi. The risk is increased when patients have previously undergone surgical procedures, such as total colectomy with ileostomy, small bowel resection, or intestinal bypass. ${ }^{5}$ Previous studies have reported that the prevalence of renal calculi is $7 \%-15 \%$ in patients with IBD, ${ }^{10}$ but many of those studies involved populations in which the rates of intestinal resection were high. In patients with IBD (having previously undergone surgery or not), it is important that this complication be investigated in a timely manner in order to prevent chronic kidney disease, as demonstrated in previous studies. ${ }^{10,11}$ Ultrasound is highly effective in showing large stones $(>5 \mathrm{~mm})$, and coupled with its safety relative to computed tomography, is the preferred screening method for renal calculi in asymptomatic populations. ${ }^{12,13}$

In this study, we demonstrated a high prevalence of asymptomatic renal calculi detected by ultrasound in a community-based population of patients with IBD. This rate is higher than that expected in the general population, as well as being higher that the approximately $7 \%-15 \%$ reported in patients with Crohn's disease of the terminal ileum. There are few data regarding the mechanisms of nephrolithiasis in patients with IBD who have not undergone prior resection. A recent study conducted in Brazil by Pontes et al showed that patients with Crohn's disease who had undergone surgery were more likely to develop renal calculi than were those who had not, and that the incidence of calcium oxalate stones was higher in the former group, the difference being statistically significant. ${ }^{14}$ This study differed from ours, as the percentage of patients who had undergone prior surgery was $44.8 \%$. $^{12,14}$

Among patients with Crohn's disease in our study, only ileocolonic disease, and not ileal disease in general, was a significant risk factor for renal calculi. These data clearly show that not only previous surgery but also the extent of disease contributes to nephrolithiasis, and that more extensive disease translates to more severe diarrhea. Therefore, patients with extensive disease should be investigated regardless of their surgical status.

Among the patients with ulcerative colitis and renal calculi, females predominated $(P=0.012)$. We believe that this was due to the fact that more females than males presented with active disease at the first medical appointment. Disease activity played an extremely important role in the formation of renal calculi in patients with ulcerative colitis (odds ratio $4.2,95 \%$ confidence interval $1.1-15, P=0.02$ ). This might have been due to the number of episodes of diarrhea, which could have led to an increase in urinary volume and greater urinary electrolyte loss due to dehydration, a situation that is not uncommon in these patients.

The rates of renal calculi detected in the present study were higher than those described in the literature, even using an imaging modality that may miss stones $<5 \mathrm{~mm}$ in size. There are two possibilities that may explain this finding. First, prior studies in IBD did not screen for nephrolithiasis in asymptomatic populations, so the relative prevalence in this population is less well defined. Second, the patients all came from a region where cattle ranches are a dominant industry, so high meat consumption might have contributed to the results, given that high dietary protein intake has been associated with renal stone formation. However, it should be borne in mind that we did not investigate factors such as diet and body mass index. In addition, it should be taken into consideration that community-based centers such as our facility generally receive patients who have never received specialist care, so patients present with more extensive or more severe disease. 
The limitations of this study include a small population size, not being powered for small differences, few patients who had surgery, no evaluation of stone composition or renal function, and selection bias in referral practice. Strengths include it being a community-based cohort with prospective enrollment and a well characterized population.

The results of the present study highlight the prevalence of nephrolithiasis in patients with Crohn's disease or ulcerative colitis, regardless of their surgical status. Specialists should consider this diagnosis in patients with unexplained renal dysfunction, abdominal pain, or recurrent urinary tract infection, and should adopt a multidisciplinary approach in these patients in order to prevent complications.

\section{Disclosure}

The authors report no conflicts of interest in this work.

\section{References}

1. Stamatelou KK, Francis ME, Jones CA, Nyberg LM, Curhan GC. Time trends in reported prevalence of kidney stones in the United States: 1976-1994. Kidney Int. 2003;63(5):1817-11823.

2. Curhan GC, Willett WC, Rimm EB, Stampfer MJ. A prospective study of dietary calcium and other nutrients and the risk of symptomatic kidney stones. N Engl J Med. 1993;328(12):833-838.

3. Clark JY, Thompson IM, Optenberg SA. Economic impact of urolithiasis in the United States. J Urol. 1995;154(6):2020-2024.
4. Curhan GC, Willett WC, Knight EL, Stampfer MJ. Dietary factors and the risk of incident kidney stones in younger women: Nurses' Health Study II. Arch Intern Med. 2004;164(8):885-891.

5. Parks JH, Worcester EM, O'Connor RC, Coe FL. Urine stone risk factors in nephrolithiasis patients with and without bowel disease. Kidney Int. 2003;63(1):255-265.

6. Worcester E, Parks JH, Josephson MA, Thisted RA, Coe FL. Causes and consequences of kidney loss in patients with nephrolithiasis. Kidney Int. 2003;64(6):2204-2213.

7. Kumar R, Ghoshal UC, Singh G, Mittal RD. Infrequency of colonization with Oxalobacter formigenes in inflammatory bowel disease: possible role in renal stone formation. $J$ Gastroenterol Hepatol. 2004;19(12):1403-1409.

8. Bansal AD, Hui J, Goldfarb DS. Asymptomatic nephrolithiasis detected by ultrasound. Clin J Am Soc Nephrol. 2009;4(3):680-684.

9. Van Assche G, Vermeire S, Rutgeerts P. The potential for disease modification in Crohn's disease. Nat Rev Gastroenterol Hepatol. 2010;7(2):79-85.

10. Andersson H, Bosaeus I, Fasth S, Hellberg R, Hulten L. Cholelithiasis and urolithiasis in Crohn's disease. Scand $J$ Gastroenterol. 1987;22(2):253-256.

11. Cirillo M, Iudici M, Marcarelli F, Laudato M, Zincone F. Nephrolithiasis in patients with intestinal diseases. G Ital Nefrol. 2008;25(1):42-48. Italian.

12. Jin DH, Lamberton GR, Broome DR, et al. Effect of reduced radiation $\mathrm{CT}$ protocols on the detection of renal calculi. Radiology. 2010;255(1):100-107.

13. Mugiya S. Guidelines on urolithiasis: update of diagnosis and treatment. Hinyokika Kiyo. 2012;58(12):703-706. Japanese.

14. Viana ML, Pontes RM, Garcia WE, Favero ME, Prete DC, Matsuo T. Crohn's disease and kidney stones: much more than coincidence? Arq Gastroenterol. 2007;44(3):210-214.

\section{Publish your work in this journal}

The International Journal of Nephrology and Renovascular Disease is an international, peer-reviewed open-access journal focusing on the pathophysiology of the kidney and vascular supply. Epidemiology, screening, diagnosis, and treatment interventions are covered as well as basic science, biochemical and immunological studies. The journal welcomes original research, clinical studies, reviews \& evaluations, expert opinion and commentary, case reports and extended reports. The manuscript management system is completely online and includes a very quick and fair peerreview system, which is all easy to use. Visit http://www.dovepress.com/ testimonials.php to read real quotes from published authors. 